\title{
Effect of the Gravel Zone Thickness Created in the Deep Well Test Simulation on the Operating Characteristics of the Pump and Head Loss
}

\author{
Nuri ORHAN ${ }^{1}$ \\ Osman ÖZBEK ${ }^{2}$ \\ Ali Yavuz ŞEFLEK ${ }^{3}$
}

\begin{abstract}
This study was conducted in a deep well simulator used for typical irrigation studies. In this work, the changes in the pump flow rate, drawdown, noise level, and pump pressures were analyzed for three different gravel zone thicknesses used in the well.

From the study, it was found that a high gravel zone thickness increased the well's drawdown levels during pumping. For drawdown values of 40, 45, 50 and $55 \mathrm{~m}^{3} \mathrm{~h}^{-1}$, an increase in the gravel thickness by $10 \mathrm{~cm}$ increased these values by $2.92,2.41,2.38$ and 2.37 times, respectively. When the gravel thickness was doubled (from $5 \mathrm{~cm}$ to $10 \mathrm{~cm}$ ), the hydraulic conductivity decreased by about half and head loss doubled. As a result, gravel thickness directly affected the drawdown rate of the pump. It was shown that different drawdown values resulting due to different gravel thicknesses should be taken into consideration when placing the pump in a deep well.
\end{abstract}

Keywords: Irrigation deep well, gravel zone thickness, pumping, drawdown, head losses, hydraulic conductivity.

\section{INTRODUCTION}

Deep wells, which have an important place in agricultural irrigation, are dug by drilling and are of different diameters. In addition, these wells are equipped with closed or screen pipes.

Note:

- This paper was received on February 20, 2020 and accepted for publication by the Editorial Board on May 23, 2020.

- Discussions on this paper will be accepted by January 31, 2022.

- https://dx.doi.org/10.18400/tekderg.691948

1 University of Selcuk, Dep. of Agricultural Machinery and Technologies Engineering, Konya, Turkey nuriorhan@selcuk.edu.tr - https://orcid.org/0000-0002-9987-1695

2 University of Selcuk, Dep. of Agricultural Machinery and Technologies Engineering, Konya, Turkey ozbek@selcuk.edu.tr - https://orcid.org/0000-0003-0034-9387

3 University of Selcuk, Dep. of Agricultural Machinery and Technologies Engineering, Konya, Turkey seflek@selcuk.edu.tr - https://orcid.org/0000-0003-1009-6635 
The area around the screen pipe is filled with gravel material and increases the filtering efficiency.

In addition, to prevent the pumping of foreign materials such as sand or silt, the gravel is also placed to support the aquifer.

Size is important when choosing gravel material [1]. The suitable particle size of the gravel material as compared to the aquifer material substantially prevents sand from entering the well $[2,3]$.

It is necessary to have at least $35 \%$ of the porosity ratio of the gravel material used [4].

The thickness of the gravel placed in the well should generally be between $7.5 \mathrm{~cm}$ and $20 \mathrm{~cm}$ $[1,2,5]$. Sterrett $[6]$ in their work stated that the gravel thickness should not exceed $12.5 \mathrm{~cm}$ and the optimum thickness should be $7.6 \mathrm{~cm}$.

Driscoll [7] reported that the maximum gravel thickness should be about $20 \mathrm{~cm}$. Using large quantities of gravel does not increase the efficiency of the well significantly and does not prevent more foreign materials (such as the sand from the sand formation) from entering the well [2].

The drawdown during pumping from irrigation wells is the sum of head losses caused by parameters such as aquifer loss, aquifer thickness, gravel pack, and screen [8]. In other words, the head losses due to the turbulent water flow around the filtered well are the predominant factor in the drawdown [9].

In this study, the effects of different gravel zone thicknesses on the well's water level during pumping decrease or drawdown $(\Delta)$, the pump noise level $(\mathrm{G})$, the pump inlet $(\mathrm{Pe})$, and the outlet pressure $(\mathrm{Pb})$ were investigated. In addition, different drawdown levels observed for wells having different gravel thicknesses have been associated with head losses. The head losses caused by the pump and measurement pipes have been neglected.

\section{MATERIALS AND METHODS}

The study was carried out using the Deep Well Testing Simulator at the Selcuk University Faculty of Agriculture, Agricultural Machinery and Technology Engineering. The technical specifications of the equipment used in the test tower are given in Table 1.

Table 1 - Some technical specifications of the measuring instruments

\begin{tabular}{ll}
\hline Pump & Nominal diameter 6"-7"-8", radial wheel, $4.5 \mathrm{~mm}$ terminal opening \\
\hline Electric & Suver, 380 V, $8.2 \mathrm{~A}, 50 \mathrm{~Hz}, 28691 / \mathrm{min}, 4.5 \mathrm{~kW}$, shaft diameter :25 \\
Machine & mm, water-cooler, $3 \times 2.5 \mathrm{~mm}^{2}$ cable cross-section \\
\hline Flow meter & S MAG $100 \mathrm{TIP}, \mathrm{DN} 80 / \mathrm{H} / 316$ electromagnetic flow meter, 220 V \\
& $\begin{array}{l}\text { power supply, digital indicator Adjustable between } 4-20 \mathrm{~m} / \mathrm{A} \text { plus. } \\
\text { Operational flow-rates } 1-280 \mathrm{~m}^{3} / \mathrm{h} \text {, operational pressure } 16 \text { bars. }\end{array}$ \\
\hline Manometer & WİKA, $0-10$ bar, $4-20 \mathrm{~m} / \mathrm{A}$ output. \\
\hline
\end{tabular}




\begin{tabular}{ll}
\hline Level Sensor & Hydrotechnik model, 010 type/1.5 V \\
\hline \multicolumn{1}{c}{ Table 1 - Some technical specifications of the measuring instruments (continue) } \\
\hline Temperature & Truck model, 10-24 VDC, $-50 \ldots 100{ }^{\circ} \mathrm{C}, 4-20 \mathrm{~mA}$ output. \\
Sensor & \\
\hline Noise Sensor & $\mathrm{CT}-2012$ model, input $4 \mathrm{~mA}, \mathrm{DC} 24 \mathrm{~V}$ power supply output indicator. \\
& Sound level Transmitter model: TR-SLT1A4, Measurement range:30- \\
& $80 \mathrm{~dB}, 50-100 \mathrm{~dB}, 80-130 \mathrm{~dB}$, output $4-20 \mathrm{~mA}, 90-260 \mathrm{ACV}$ \\
& $50 \mathrm{~Hz} / 60 \mathrm{~Hz}$, Operation temperature $0-50{ }^{\circ} \mathrm{C}$. \\
\hline Computer & Asus Intel core i7. \\
\hline
\end{tabular}

In the experiments, approximately $2 \mathrm{~m}^{3}$ clean and washed gravel was used to fill different gravel casing pipes. The gravel used is shown in Figure 1.

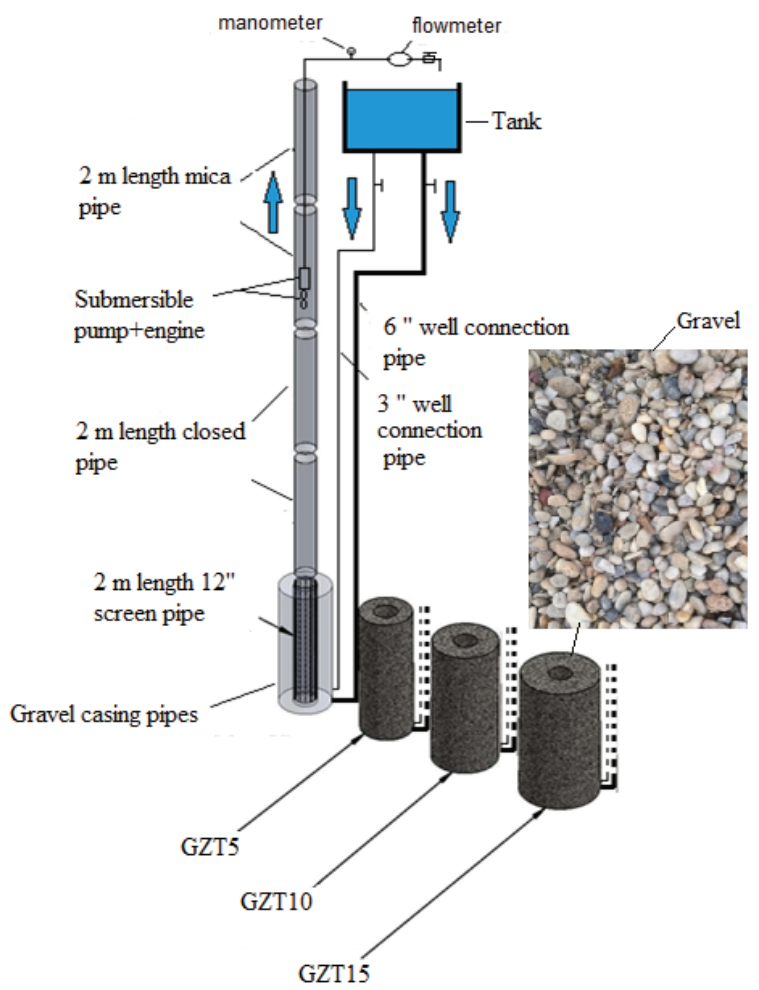

Figure 1 - Well equipment and working principle for gravel zone thickness

The average of some of the physical properties of the gravel, determined from the measurements made on 100 gravel samples taken from the gravel pile, are shown in Table 2 $[10,11]$. 
From Table 2, it can be seen that $76 \%$ of the gravel used in the experiments is between $7-15$ $\mathrm{mm}$. Furthermore, the porosity of the gravel using in the well is over $35 \%$.

The inlet pressure $(\mathrm{Pe})$ of the pump was measured with a U-type differential pressure gauge placed at the suction nozzle. For the U-type differential pressure gauge, a $2 \mathrm{~m}$ long and $6 \mathrm{~mm}$ diameter transparent hose and $200 \mathrm{~g}$ mercury were used.

In the experiments, a $4 \mathrm{~m}$ long-closed pipe, $4 \mathrm{~m}$ long mica pipe and a $2 \mathrm{~m}$ long and 12" diameter vertical oblong filter were used. This combination was kept constant in all gravel experiments. The gravel was filled around the screen pipe with the help of specially prepared gravel casing pipes.

Different thicknesses of gravel were piled in each well and the wells were labeled GZT5, GZT10, and GZT15, corresponding to gravel zone thicknesses of $5 \mathrm{~cm}, 10 \mathrm{~cm}$, and $15 \mathrm{~cm}$, respectively. In this way, three different well types (GZT5, GZT10, GZT15) were formed.

Water inlet to the deep well constructed for the experiments was provided from the tank consisting of 6" and 3" diameter pipes. On establishing these connections, the deep well test tower works according to the compound containers method (Figure 1). The measurement and calculation of the pump's operating characteristics were made according to EN ISO 9906 and the noise levels were measured according to EN ISO $3740[12,13]$.

Table 2 - Some physical properties of gravel used in experiments

\begin{tabular}{ll}
\hline Physical property & Average value \\
\hline Bulk density $\left(\mathrm{kg} \mathrm{dm}^{-3}\right)$ & 1.54 \\
Density $\left(\mathrm{kg} \mathrm{dm}^{-3}\right)$ & 2.75 \\
Porosity (\%) & 44 \\
Thickness (mm) & 14.3 \\
Length (mm) & 19.6 \\
Thickness (mm) & 9.1 \\
Geometric diameter (mm) & 13.5 \\
Globularness (\%) & 70 \\
Natural agglomeration angle (o) & 22.76 \\
Metal-gravel static friction coefficient (-) & 41.9 \\
Frequency distribution of particles in terms of geometric diameter \\
7.68 mm (min.) -10.00 mm (\%) & 8 \\
10.01 mm -13.50 mm (\%) & 46 \\
13.51 mm -15.00 mm (\%) & 22 \\
15.01 mm -18.00 mm (\%) & 12 \\
18.01 mm-21.94 mm (max.) (\%) & 12 \\
\hline
\end{tabular}


The noise level was measured by placing the noise measurement device from the tower control center platform approximately $1 \mathrm{~m}$ below the space between the pump column and the plexiglass pipe [14-16].

The hydraulic conductivity $(\mathrm{K})$ of the different well types was calculated according to the Darcy law (Darcy, 1856).

In each of the well types having different gravel zone thicknesses, with the submersible pump (D) operating at the optimum operating speed, for five different flow ranges $(40,45,50,55$, $60 \mathrm{~m}^{3} \mathrm{~h}^{-1}$ ) the drawdown $(\Delta)$ /submergence $(\mathrm{S})$, pump noise level $(\mathrm{G})$, pump outlet pressure $(\mathrm{Pb})$, pump inlet pressure $(\mathrm{Pe})$, ambient temperature $\left(\mathrm{T}_{1}\right)$ and water temperature $\left(\mathrm{T}_{2}\right)$ values were measured (Figure 2). After the pump was run at a particular flow rate, the initial values were recorded and then the other flow values were attempted.

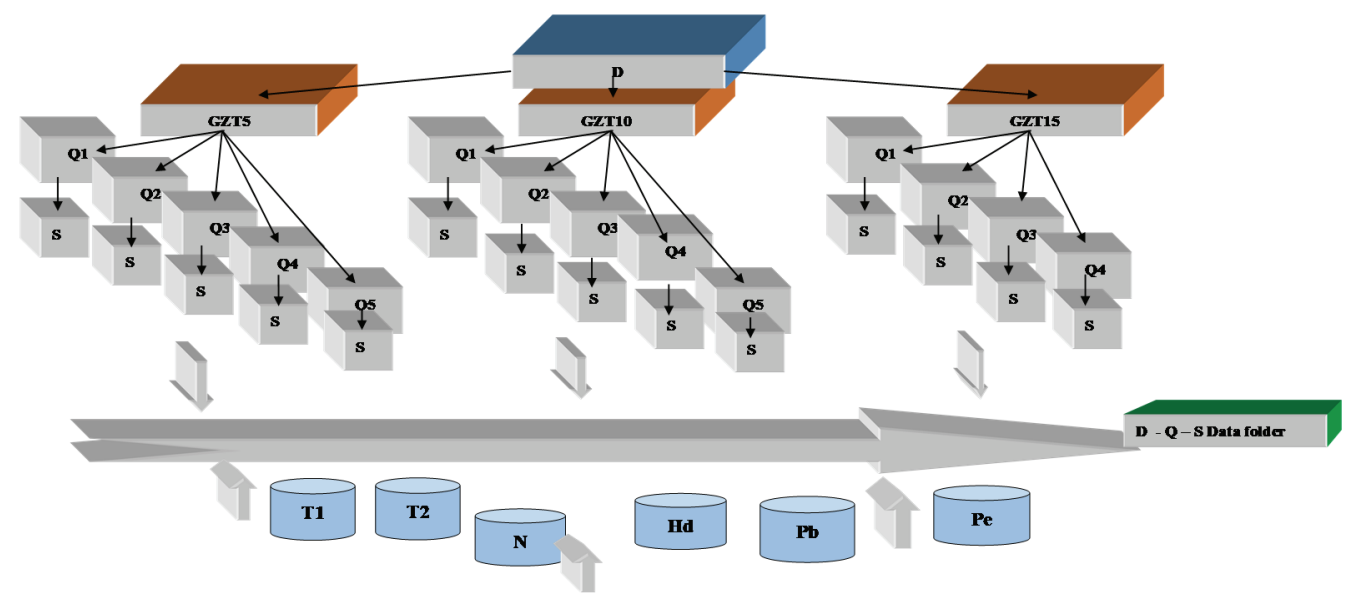

Figure 2 - Trial plan

Software and automation systems were made to record the measured data. The information received from the sensors located in the system was wirelessly transferred to the central computer via a data acquisition card and a Bluetooth module. The information stored in the central computer for the required range was recorded with a suitable name that was given by the operator via the software interface. Record action was set to record one measurement per second. After the pump entered the working regime, the record-process was started and 50 data recordings were taken from one sensor.

The experiments were carried out at a plunge depth (constant hydraulic head) of $188 \mathrm{~cm}$. The measurement of the drawdown $(\Delta)$ was made by the level meter.

\section{RESULTS AND DISCUSSION}

During the experiments, the average air and water temperatures were $15{ }^{\circ} \mathrm{C}$ and $12{ }^{\circ} \mathrm{C}$, respectively. 
The experiments were started under a constant hydraulic head of $188 \mathrm{~cm}$ and at a level of 89 $\mathrm{cm}$ of static water.

\subsection{Effect of the Gravel Zone Thickness on the Drawdown}

The results of the least square difference (LSD) test and the averages of the drawdown levels corresponding to the different thickness of the gravel zone in each well type are given in Table 3.

Table 3 - The different gravel zone thickness and values drawdowns (cm)

\begin{tabular}{ccccc}
\hline Q & GZT5 & GZT10 & GZT15 & Q \\
\hline $\mathbf{4 0}$ & $41.00^{\mathbf{k}}$ & $65.67^{\mathrm{h}}$ & $94.02^{\mathrm{e}}$ & $66.91^{\mathrm{d}}$ \\
$\mathbf{4 5}$ & $49.67^{\mathrm{j}}$ & $82.57^{\mathrm{f}}$ & $119.97^{\mathrm{c}}$ & $84.07^{\mathrm{c}}$ \\
$\mathbf{5 0}$ & $62.17^{1}$ & $100.03^{\mathrm{d}}$ & $148.02^{\mathrm{b}}$ & $103.41^{\mathrm{b}}$ \\
$\mathbf{5 5}$ & $74.00^{\mathrm{g}}$ & $119.13^{\mathrm{c}}$ & $176.03^{\mathrm{a}}$ & $123.05^{\mathrm{a}}$ \\
\cline { 2 - 3 } & \multicolumn{5}{c}{ LSD $=\mathbf{2 . 2 8 4}$} & $\mathbf{L S D}=\mathbf{1 . 3 1 8}$ \\
\hline \multirow{5}{*}{ GZT } & $56.71^{\mathrm{c}}$ & $91.85^{\mathrm{b}}$ & $134.52^{\mathrm{a}}$ \\
\cline { 2 - 4 } & $\mathbf{L S D}=\mathbf{1 . 1 4 2}$ \\
\end{tabular}

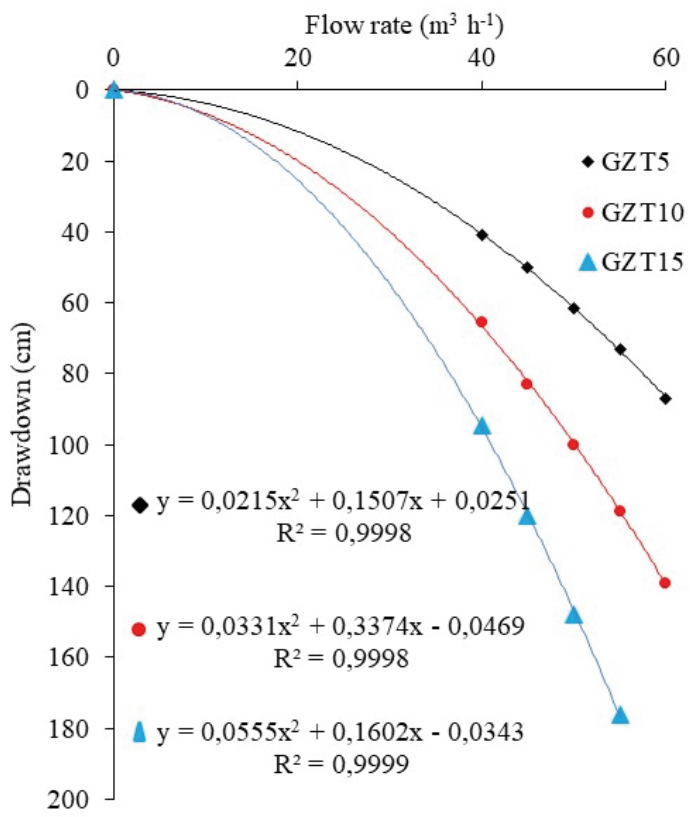

Figure 3 - The relationship between gravel zone thickness and drawdown 
The data could not be retrieved due to too much drawdown in the $60 \mathrm{~m}^{3} \mathrm{~h}^{-1}$ flow rate in the well type GZT15. Thus, it has not been included in Table 3.

The values of the drawdown in wells having different gravel zone thicknesses are plotted in Figure 3.

The highest drawdown measured was $134.52 \mathrm{~cm}$ in the GZT15 well type with the least drawdown of $56.71 \mathrm{~cm}$ in GZT5 well type. The measured drawdown values for constant flow rates were found to be $66.91 \mathrm{~cm}$ at a flow rate of $40 \mathrm{~m}^{3} \mathrm{~h}^{-1}, 84.07 \mathrm{~cm}$ at a flow rate of $45 \mathrm{~m}^{3}$ $\mathrm{h}^{-1}, 103.41 \mathrm{~cm}$ at a flow rate of $50 \mathrm{~m}^{3} \mathrm{~h}^{-1}$ and $123.05 \mathrm{~cm}$ at a flow rate of $55 \mathrm{~m}^{3} \mathrm{~h}^{-1}$. It can be seen from Table 3 that there is a statistically significant difference between the values. On determining the variance of the drawdown values, the flow, gravel zone thickness, and the interaction of these two parameters were found to be statistically different $(\mathrm{P}<0.01)$. As the flow rate in all the well types increased, the drawdown level in them increased as well. The $\mathrm{R}^{2}$ values corresponding to this increase is very high. From Fig. 3, it can be clearly seen that increasing the gravel thickness at the same flow rate increases the drawdown levels.

\subsection{Hydraulic Conductivity of the Different Well Types, Hydraulic Conductivity of the Gravel, and Reynolds Number}

The hydraulic conductivity of the gravel material used and the different well types constructed were calculated separately. The hydraulic conductivity of gravel was calculated using the Hazen-Williams (1892-1911) equation. This equation is based on the relationship between the grain size and permeability and is given by Equation (1).

$$
\begin{aligned}
& k=C . d_{10}^{2}(0.7+0.03 T) \\
& C=400+40(n-26)
\end{aligned}
$$

where $\mathrm{k}$ is permeability $\left(\mathrm{m} \mathrm{s}^{-1}\right), \mathrm{d}_{10}$ is the effective grain size, which is thinner by ten percent by weight $(\mathrm{mm}), \mathrm{T}$ is the temperature of water $\left({ }^{\circ} \mathrm{C}\right), \mathrm{C}$ is the Hazen-Williams coefficient calculated according to porosity, and $\mathrm{n}$ is the porosity. The $\mathrm{d}_{10}$ value of the gravel used in the experiments was found to be $12 \mathrm{~mm}$. The average water temperature was $14{ }^{\circ} \mathrm{C}$ during the experiments. The permeability of the gravel was calculated to be $1.8 \times 10^{-1} \mathrm{~m} \mathrm{~s}^{-1}$. The hydraulic permeability coefficient of the different well types was calculated according to the Darcy law Eqn. (2) given below. According to the Darcy law, the flow rate $(\mathrm{Q})$ of the liquid passing through a medium is directly proportional to the crosssectional area (A) perpendicular to the flow, the head loss $(\Delta \mathrm{h})$ and the coefficient of hydraulic permeability coefficient $(\mathrm{K})$ and is inversely proportional to the distance traveled by the liquid $(\Delta \mathrm{L})$.

$$
\begin{aligned}
& Q=A \cdot K \cdot i \\
& i=\frac{\Delta h}{\Delta L}
\end{aligned}
$$


The values of the flow rate obtained for the different well types by applying Darcy's law are plotted in Fig. 4. The hydraulic permeability coefficient of the different well types calculated from Darcy's law has also been indicated here.

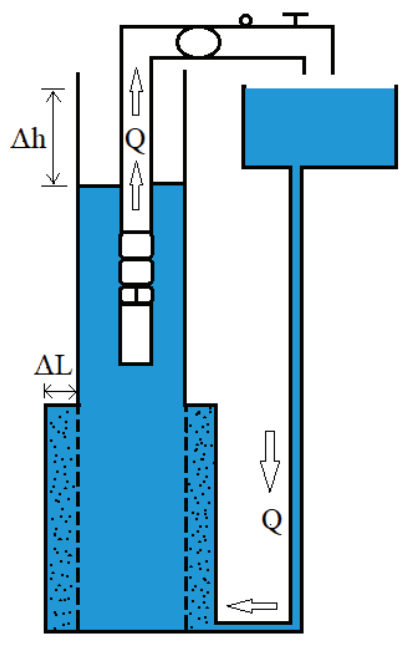

Figure 4 - Method of application of Darcy's law in well types

The relation between hydraulic permeability coefficient $(\mathrm{K})$ and the drawdown levels is shown in Fig. 5.

An increase in the gravel zone thickness was found to reduce the hydraulic permeability coefficient at a constant flow rate. Houben et al., (Houben and Hauschild [17]) reported that the lower the hydraulic conductivity, the higher is the drawdown. The average hydraulic permeability coefficient values corresponding to the GZT5, GZT10, and GZT15 well types were calculated to be $0.012,0.0036$ and 0.0016 , respectively. This difference in the hydraulic permeability coefficient values was found to be due to the different gravel zone thicknesses in the wells. The flow regime can be determined by calculating the Reynolds number, which is determined using the following expression $[4,18,19]$ :

$$
\operatorname{Re}=\frac{\rho \cdot v \cdot d}{\mu}
$$

where;

$\rho=$ Density of water $\left(\right.$ at $14{ }^{\circ} \mathrm{C}$, it is $999.85 \mathrm{~kg} \mathrm{~m}^{-3}$ ),

$\mathrm{v}=$ water inlet speed $\left(\mathrm{m} \mathrm{s}^{-1}\right)$,

$\mu=$ dynamic viscosity of water (at $14^{\circ} \mathrm{C}$, it is $0.0013097 \mathrm{~kg} \mathrm{~m}^{-1} \mathrm{~s}^{-1}$ ),

$\mathrm{d}=$ Characteristic length $(\mathrm{m})$; the average gravel grain size was taken as the characteristic length here. 
If $\operatorname{Re} \leq 10$ in porous environments, the flow is considered to be laminar [18]. If $\operatorname{Re}>100$, the flow is assumed to be turbulent $[18,20]$. In this study, the Reynolds number in all the flow values ranged between 1100 and 1800. A turbulent flow was detected in the gravel region.

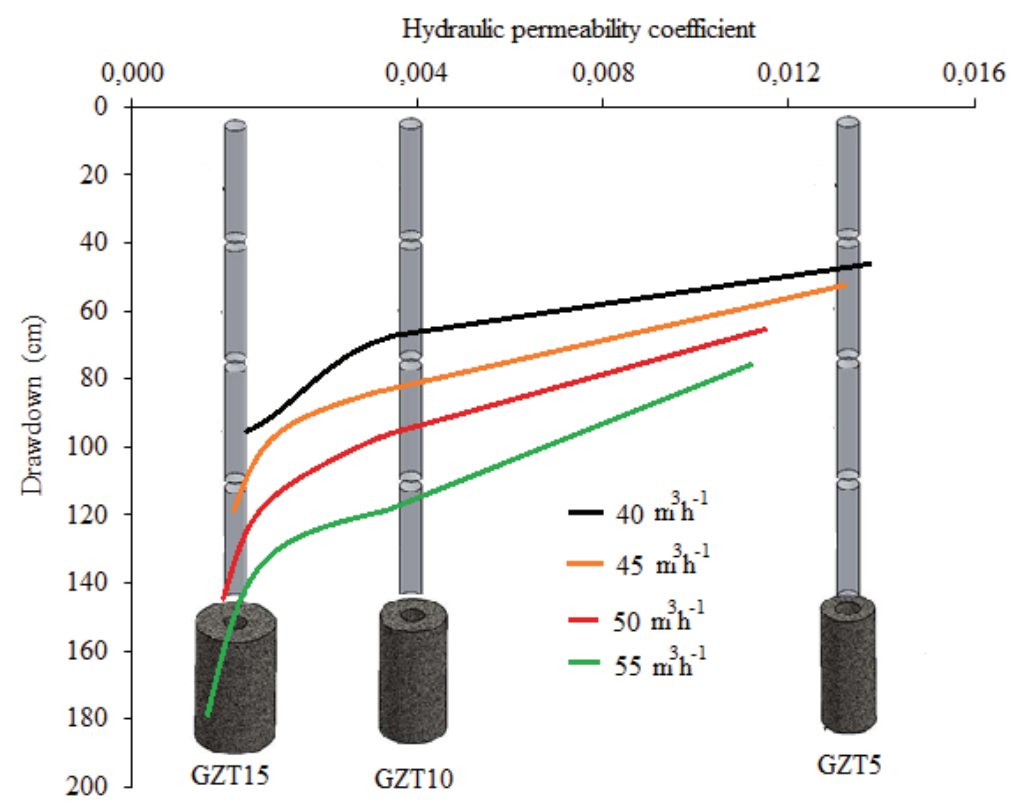

Figure 5 - The hydraulic permeability coefficient and drawdown relation of different well types

\subsection{Head Loss for Different Gravel Thicknesses}

Many researchers have stated that the drawdown in the wells corresponds to head losses [8, 20-22]. The reason for the different drawdown at the same flow rate and different gravel zone thickness in the well is caused by the head loss. These head losses are expressed as the sum of laminar and turbulent head losses. The turbulent loss is limited to the well filter area [20, 23].

For the three different well types, the head loss due to a change in the gravel thickness by 5 $\mathrm{cm}$ and $10 \mathrm{~cm}$ was considered. The head loss due to an increase in the gravel thickness by 5 $\mathrm{cm}$ was obtained from the drawdown differences in the GZT5 and GZT10 well types, while the head loss due to an increase in the gravel thickness by $10 \mathrm{~cm}$ was obtained from the drawdown differences in the GZT5 and GZT15 well types.

As a result, since all components of each well type are fixed except for the gravel thickness, the only reason the different drawdown is obtained is due to the different gravel thickness.

As a function of the flow rate, the head losses for an increase in the gravel thickness by $5 \mathrm{~cm}$ and $10 \mathrm{~cm}$ are plotted in Fig. 6. 


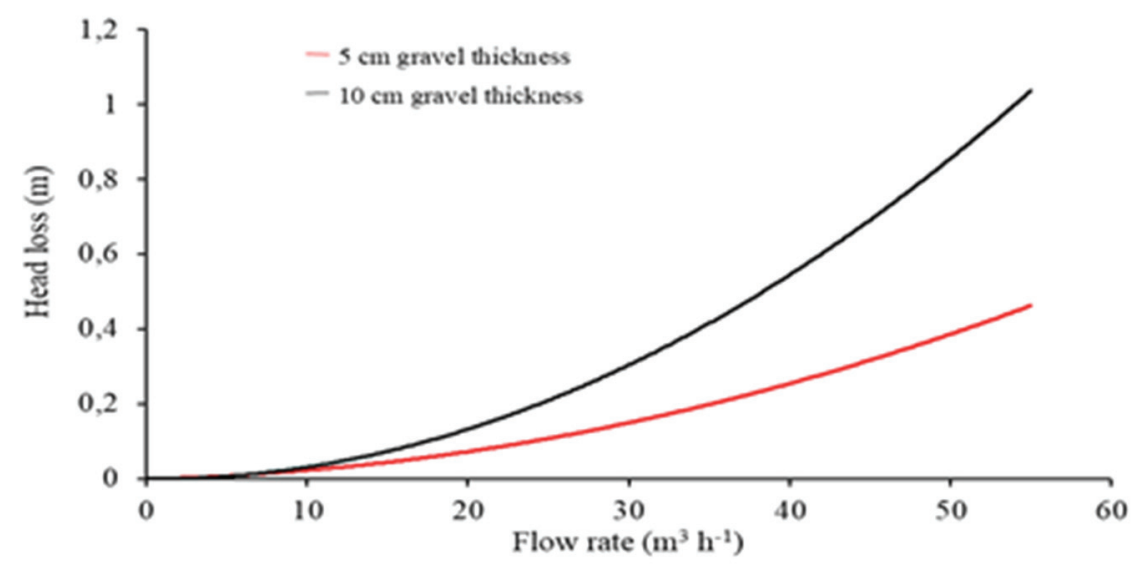

Figure 6 - Relationship between gravel thickness increase and head loss

For each flow rate, an increase in the gravel thickness by $10 \mathrm{~cm}$ caused a larger head loss as compared to the case where the gravel thickness was increased by $5 \mathrm{~cm}$ (Fig. 6). At a flow rate of $55 \mathrm{~m}^{3} \mathrm{~h}^{-1}$, a $0.46 \mathrm{~m}$ head loss corresponding to an increase in the gravel thickness by $5 \mathrm{~cm}$, was found to increase to $1.03 \mathrm{~m}$ for an increase in the gravel thickness by $10 \mathrm{~cm}$.

We explain the increased head loss with increasing gravel thickness by the distance traveled by water from the gravel to the filter under water. The head loss increases by increasing this distance, which can also be understood from the Darcy-Weisbach [24] turbulent flow equation.

Houben [20] has estimated that different gravel thicknesses cause different head losses in the case of low hydraulic conductivity wells. In his study, Byung-Woo [21] found different drawdown values for the same flow rate for the case of gravel and gravel + granular screen zones combinations. The addition of gravel to the well is shown to increase the drawdown value.

Table 4 - The drawdown values per unit cm of the gravel zone well types

\begin{tabular}{cccc}
\hline $\begin{array}{c}\mathrm{Q} \\
\left(\mathrm{m}^{3} \mathrm{~h}^{-1}\right)\end{array}$ & $\begin{array}{c}\text { GZT5-GZT10 } \\
\Delta\left(\mathrm{m} \mathrm{cm}^{-1}\right)\end{array}$ & $\begin{array}{c}\text { GZT5-GZT15 } \\
\Delta\left(\mathrm{m} \mathrm{cm}^{-1}\right)\end{array}$ & $\begin{array}{c}\text { Average } \\
\left(\mathrm{m} \mathrm{cm}^{-1}\right)\end{array}$ \\
\hline 40 & 0.049 & 0.054 & 0.051 \\
45 & 0.066 & 0.07 & 0.068 \\
50 & 0.077 & 0.087 & 0.082 \\
55 & 0.092 & 0.103 & 0.098 \\
60 & 0.104 & - & 0.104 \\
\hline
\end{tabular}


The head loss per unit gravel thickness is given in Table 4. The unit gravel width was calculated by dividing the head losses due to the increasing gravel thickness in the GZT5, GZT10, and GZT15 well types by the difference of the gravel thickness values used in these wells.

For the GZT5-GZT10 and GZT5-GZT15 well types, the head loss values per unit $\mathrm{cm}$ are close to each other.

The average rates show an increase of $0.098 \mathrm{~m} \mathrm{~cm}^{-1}$ for a flow rate of $55 \mathrm{~m}^{3} \mathrm{~h}^{-1}$ while for a flow rate of $40 \mathrm{~m}^{3} \mathrm{~h}^{-1}$, it is $0.051 \mathrm{~m} \mathrm{~cm}^{-1}$. The values of the average head loss per unit $\mathrm{cm}$ in the different well types are plotted in Fig. 7. It can be seen from the figure that the head loss per unit of gravel thickness increases as the flow rate increases. This is consistent with the work of Houben [8], where a similar observation was found.

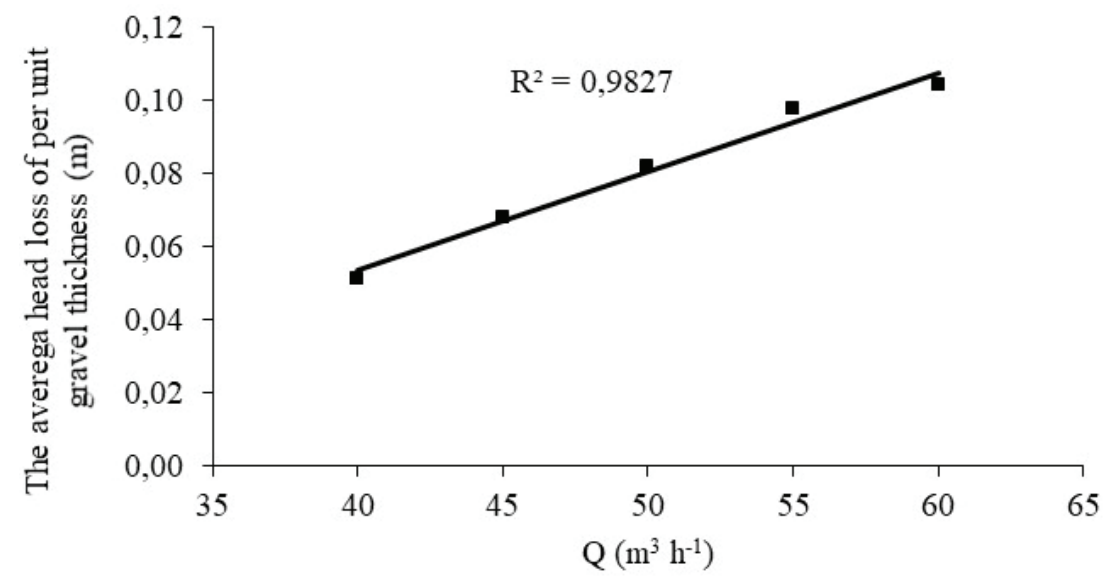

Figure 7 - Average unit gravel thickness per head loss and flow change

\subsection{The Effect of the Gravel Zone Thickness on the Noise Level}

The effect of different gravel zone thicknesses on the noise level of the pump for different flow values is illustrated in Fig. 8a.

The figure shows that an increase in the gravel zone thickness does not have a significant effect on the noise level. In a previous report, Çalışır, et al. [25] stated that the noise level of the pump decreased for the flow rate corresponding to the optimum efficiency point of the pump, which in their study was found to be $48-52 \mathrm{~m}^{3} \mathrm{~h}^{-1}$. The optimum efficiency point of the pump we used in the study was measured as $50 \mathrm{~m}^{3} \mathrm{~h}^{-1}$. At the optimum efficiency point flow rate $\left(50 \mathrm{~m}^{3} \mathrm{~h}^{-1}\right)$, increasing the gravel zone thickness led to an increase in the noise level (Fig. 8a).

The average noise levels in the pump fixed in the GZT5, GZT10 and GZT15 well types for flow rates of $40,45,50$ and $55 \mathrm{~m}^{3} \mathrm{~h}^{-1}$ were measured to be $74.5,75.1,72.7$ and $76.3 \mathrm{~dB}$, respectively. The minimum noise level was obtained at the optimum efficiency point of the pump. 
The average of the noise levels obtained in the GZT5, GZT10, and GZT15 well types for all flow rates were found to be $73.05,75.30$, and $76.68 \mathrm{~dB}$, respectively. The average of the noise levels obtained at different flow rates of the pump increased as the gravel thickness increased.
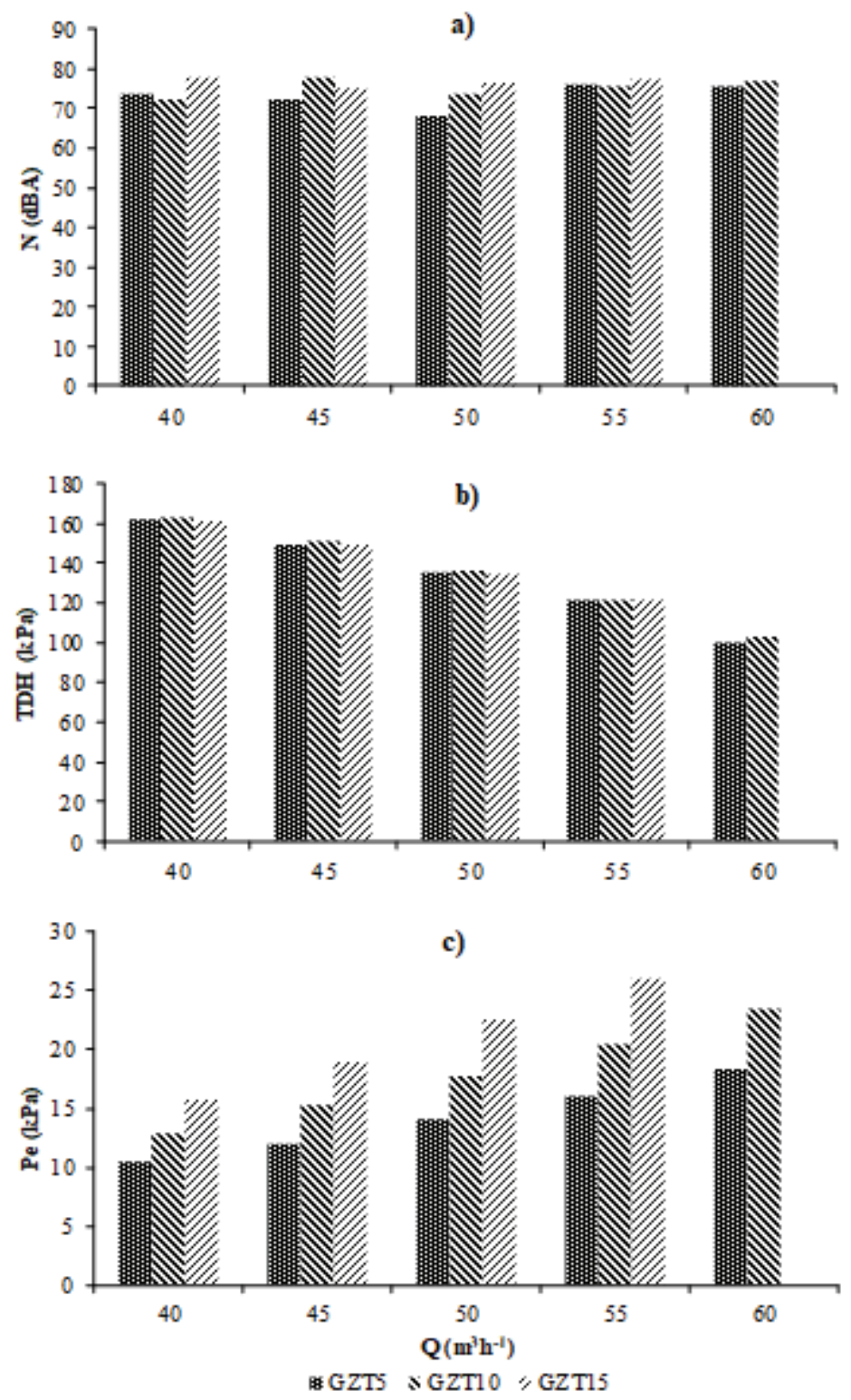

Figure 8 - Difference between gravel zone thickness, flow rate, and noise 


\subsection{Effect of the Gravel Zone Thickness on the Total Dynamic Head (TDH) and TDH Components of the Pump}

The effect of the gravel zone thickness on the TDH developed by the pump is shown in Fig. $8 b$.

From the figure, it is seen that as the flow rate in the three well types increases, the TDH rates are seen to decrease. In the case of constant flow rates, the effect of gravel zone thickness was not observed.

The numerical values of TDH and TDH components as a function of the different gravel zone thicknesses are given in Table 5.

Table 5 - TDH (total dynamic head) and TDH components in different gravel zone thicknesses and flow rates

\begin{tabular}{cccccc}
\hline & $\begin{array}{c}\mathbf{Q} \\
\left(\mathbf{m}^{\mathbf{3}} \mathbf{h}^{-\mathbf{1}} \mathbf{)}\right.\end{array}$ & $\begin{array}{c}\mathbf{P}_{\mathbf{b}} \\
\mathbf{( k P a )}\end{array}$ & $\begin{array}{c}\mathbf{H}_{\mathbf{d}} \\
(\mathbf{m})\end{array}$ & $\begin{array}{c}\mathbf{V}^{\mathbf{2}} \mathbf{2 g} \\
\mathbf{( m )}\end{array}$ & $\begin{array}{c}\text { TDH } \\
(\mathbf{k P a})\end{array}$ \\
\hline \multirow{6}{*}{ GZT5 } & 40.1 & 146.5 & 1.30 & 0.27 & 161.9 \\
& 45.0 & 132.4 & 1.39 & 0.34 & 149.4 \\
& 50.1 & 118.7 & 1.51 & 0.43 & 138.1 \\
& 55.1 & 100.4 & 1.63 & 0.52 & 121.4 \\
& 60.1 & 76.6 & 1.76 & 0.61 & 99.9 \\
\hline \multirow{6}{*}{ GZT10 } & 40.2 & 144.8 & 1.55 & 0.27 & 162.7 \\
& 45.1 & 130.3 & 1.72 & 0.35 & 150.6 \\
& 50.2 & 113.2 & 1.89 & 0.43 & 136.4 \\
& 54.9 & 94.5 & 2.08 & 0.52 & 120.2 \\
& 60.0 & 74.3 & 2.28 & 0.62 & 102.7 \\
\hline \multirow{6}{*}{ GZT15 } & 40.0 & 140.8 & 1.84 & 0.27 & 161.5 \\
& 44.9 & 125.2 & 2.09 & 0.35 & 149.1 \\
& 50.1 & 106.8 & 2.37 & 0.43 & 134.2 \\
& 55.0 & 90.5 & 2.65 & 0.52 & 121.5 \\
\hline
\end{tabular}

From the table, it is observed that as the gravel zone thickness is increased while the flow rate is constant, the TDH and velocity (or the kinetic energy) do not change, the pump outlet pressure $(\mathrm{Pb})$ decreases and the dynamic height $(\mathrm{Hd})$ rate increases. The reason for these changes is the drawdown.

Also, on examining the effect of the gravel zone thickness and flow rate on the inlet pressure, the pump inlet pressure rates show an increase both as the gravel zone thickness increases for a constant flow rate as well as when the flow rate increases for a constant gravel zone thickness (Fig. 8c). 


\section{CONCLUSION}

The arrangement of the gravel zone in the well design is one of the effective parameters pertaining to head losses while pumping from a well. During the pumping process, different gravel zone thicknesses were observed giving rise to different head losses occurring at the well inlet. These head losses caused different drawdown for the same flow rate of the pump.

A $10 \mathrm{~cm}$ increase in the gravel thickness for flow rates of $40,45,50$ and 55 $\mathrm{m}^{3} \mathrm{~h}^{-1}$ caused an increase by $2.92,2.41,2.38$ and 2.37 times, respectively in the drawdown values. The difference between the average values of the drawdown rates has been found to be statistically significant. Furthermore, the drawdown rates per unit gravel thickness were found to increase with increasing flow rate.

Hydraulic permeability coefficient was found to decrease in well types having higher gravel thickness. The average head loss per unit of gravel thickness for all flow rates was found to be $0.0805 \mathrm{~m} \mathrm{~cm}^{-1}$. When the gravel thickness doubled (from $5 \mathrm{~cm}$ to $10 \mathrm{~cm}$ ), the hydraulic conductivity decreased by about half and the head loss doubled.

An increase in the gravel thickness resulted in an increase in the average noise levels at different flow rates of the pump. As the increase in gravel thickness affects the drawdown, the pump has a reduced outlet pressure rate and requires an increased inlet pressure rate. However, the total dynamic head of the pump does not change depending on the gravel thickness.

As a result, different gravel thicknesses directly affect the drawdown rate of the pump. The dependence of the head losses on the gravel zone thickness, which is one of the important factors in a well design, has emerged from the experiments in this work with the deep well testing unit. In addition, well design analyses were performed for the gravel type used in the experiments.

Firms designing wells and Engineers working in the company can benefit from the results of this study. Experts who want to make use of this context can choose the pump by examining the effects of gravel zone thickness on the well design and the reduction in the well.

\section{Symbols}

$\begin{array}{lll}\rho & =\text { Water density }\left(\mathrm{kg} \mathrm{m}^{-3}\right) \\ \mu & = & \text { dynamic viscosity }\left(\mathrm{kg} \mathrm{m}^{-1} \mathrm{~s}^{-1}\right) \\ \Delta & = & \text { Drawdown }(\mathrm{cm}) \\ \mathrm{Hd} & = & \text { Dynamic head }(\mathrm{mm}) ; \\ \mathrm{G} & = & \text { Pump noise level }(\mathrm{dBA}) ; \\ \text { GZT5 } & =5 \mathrm{~cm} \text { gravel zone thicknesses } \\ \text { GZT10 } & 10 \mathrm{~cm} \text { gravel zone thicknesses } \\ \text { GZT15 } & \quad 15 \mathrm{~cm} \text { gravel zone thicknesses } \\ \mathrm{K} & =\text { Hydraulic conductivity }\left(\mathrm{m} \mathrm{s}^{-1}\right) ;\end{array}$ 


$$
\begin{array}{ll}
\mathrm{i} & =\text { hydraulic gradient }(-) \\
\mathrm{Re} & =\text { Reynolds number }(-) \\
\mathrm{Pb} & =\text { Output pressure }(\mathrm{kPa}) ; \\
\mathrm{Pe} & =\text { Inlet pressure }(\mathrm{kPa}) ; \\
\mathrm{Q} & =\text { Flow rate }\left(\mathrm{m}^{3} \mathrm{~h}^{-1}\right) ; \\
\mathrm{S} & =\text { Submergence }(\mathrm{mm}) ; \\
\mathrm{V} & =\text { water inlet speed }\left(\mathrm{m} \mathrm{s}^{-1}\right) \\
\mathrm{TDH} & =\text { Total dynamic head }(\mathrm{kPa}) ; \\
\mathrm{T} 1 & =\text { Ambient temperature }\left({ }^{\circ} \mathrm{C}\right) ; \\
\mathrm{T} 2 & =\text { Water temperature }\left({ }^{\circ} \mathrm{C}\right) ;
\end{array}
$$

\section{References}

[1] K. Rafferty, "Specification of water wells," American Society of Heating, Refrigerating and Air-Conditioning Engineers Transactions, vol. 107(2), 2001.

[2] B. Boman, S. Shukla, and J. Hardin, "Design and construction of screened wells for agricultural irrigation systems," EDIS University of Florida, 2003.

[3] Çebi $T$, "Design Techniques in Drinking and Potable Water Supply Wells in Groundwater.," Journal of Geological Engineering, vol. 44-45, 7, 1994 p. 70-81.

[4] G. J. Houben, J. Wachenhausen, and C. R. G. Morel, "Effects of ageing on the hydraulics of water wells and the influence of non-Darcy flow," Hydrogeology Journal, vol. 26, no. 4, 2018, p. 1285-1294.

[5] K. Akpınar, "Su Kuyularının Açılması ve İşletilmesi, Sorunları ve Çözümleri" ISBN 975-94033-0-7. Ankara, 1999, p.1-695

[6] R. J. Sterrett, "Groundwater and wells, 3rd edn. Johnson Screens, New Brighton, MN.," 2007.

[7] F. G. Driscoll, "Groundwater and wells, 2nd edn. Johnson Division, St. Paul, MN," 1986.

[8] G. J. Houben, "Hydraulics of water wells - head losses of individual components," Hydrogeology journal, vol. 23, no. 8, 2015, p. 1659-1675.

[9] V. Batu, Aquifer hydraulics: a comprehensive guide to hydrogeologic data analysis. John Wiley \& Sons, 1998.

[10] TS EN 1097-3, Tests for mechanical and physical properties of aggregates- Part 3: Determination of loose bulk density and voids, Turkish Standardization Institute, Ankara, 1999. 
[11] TS EN 933-3, Experiments for Geometric Properties of Aggregates.,Turkish Standardization Institute. Ankara., 2004.

[12] TS EN ISO 9906, Rotodynamic Pumps-Hydraulic Performance Acceptance Tests, Class 1 and Class 2, Turkish Standardization Institute, Ankara, 2012.

[13] TS 11146/T1, Submersible Pumps for Clean Water, Turkish Standardization Institute, Ankara, 2016.

[14] M. Binama, A. Muhirwa, and E. Bisengimana, "Cavitation effects in centrifugal pumpsA review," Binama Maxime. Int. Journal of Engineering Research and Applications, vol. 6, no. 5, 2016, p. 52-63.

[15] M. Čdina, "Detection of cavitation phenomenon in a centrifugal pump using audible sound," Mechanical systems and signal processing, vol. 17, no. 6, 2003, p. 1335-1347.

[16] M. Čudina and J. Prezelj, "Detection of cavitation in operation of kinetic pumps. Use of discrete frequency tone in audible spectra," Applied Acoustics, vol. 70, no. 4, 2009, p. 540-546.

[17] G. J. Houben and S. Hauschild, "Numerical Modeling of the Near-Field Hydraulics of Water Wells," Groundwater, vol. 49, no. 4, 2011, p. 570-575.

[18] J. Bear, Hydraulics of Groundwater. New York: Dover Publication 2007.

[19] F. Tügel, G. J. Houben, and T. Graf, "How appropriate is the Thiem equation for describing groundwater flow to actual wells?," Hydrogeology Journal, vol. 24, no. 8, 2016, p. 2093-2101.

[20] G. J. Houben, "Hydraulics of water wells-flow laws and influence of geometry," Hydrogeology Journal, vol. 23, no. 8, 2015, p. 1633-1657.

[21] K. Byung-Woo, "Effect of Filter Designs on Hydraulic Properties and Well Efficiency," Groundwater S1 (52), 2014, p. 175-185.

[22] M. Janssen Lok, "Analysis and improvement of well capacities in fine grained sand aquifers," 2013.

[23] D. E. Williams, "Modern techniques in well design," Journal-American Water Works Association, vol. 77, no. 9,1985, p. 68-74.

[24] J. L. Weisbach, Lehrbuch der ingenieur-und maschinen-mechanik (Textbook of engineering and machine mechanics). Vieweg, 1863.

[25] S. Çalışır, T. Eryılmaz, H. Hacıseferoğulları, and H. O. Mengeş, "Noise in Centrifugal Pumps," Journal of Agricultural Machinery Science, vol. 3, no. 2, 2007, p. 105-110. 